\title{
A FORMAÇÃO EM DIREITOS HUMANOS A PARTIR DE UM OLHAR SOBRE O CORPO DOCENTE DA ACADEMIA DA POLÍCIA CIVIL DE SÃO PAULO
}

\author{
JULIANA ROSA GONÇALVES MOTA
}

Pesquisadora e professora. Mestra em Estudos Avançados em Direitos Humanos pela Universidad Carlos III de Madrid. Licenciada em Educação e graduada em Letras Português-Espanhol pela Universidade de São Paulo. Graduada em Direito pela Universidade Presbiteriana Mackenzie. Delegada de Polícia da Polícia Civil de São Paulo entre 2007 a 2020.

País: Espanha Cidade: Madri

E-mail:jrgmota@sp.gov.br ORCID: https://orcid.org/0000-0003-4532-9160

\section{RESUMO}

O programa da disciplina "Direitos Humanos: Polícia Civil e a Diversidade", ministrada nos cursos de formação da Academia da Polícia Civil de São Paulo, passou por uma série de alterações ao longo dos anos, especialmente centradas na introdução de temas como gênero, raça, diversidade sexual e deficiência. A partir dessas reformulações, o presente artigo busca analisar o corpo docente responsável pela disciplina, bem como se recebeu formação inicial ou continuada para lidar com as novas demandas de ensino. Para tanto, buscou-se identificar os processos de seleção dos professores, bem como se houve programas de qualificação docente desenvolvidos pela unidade. O percurso metodológico baseou-se na pesquisa bibliográfica, com atenção para a literatura sobre formação policial e capacitação do corpo docente; documental, realizada no Diário Oficial do Estado e na legislação sobre a Academia de Polícia e, ainda, na observação participante. Constatou-se o pouco espaço que esse campo ocupa nas discussões sobre formação policial na literatura especializada e na própria Academia de Polícia, sendo poucas as iniciativas de qualificação de seus docentes, o que pode dificultar a efetiva concretização da proposta pedagógica apresentada nos novos conteúdos programáticos sobre direitos humanos.

Palavras-chave: Polícia Civil de São Paulo. Academia de Polícia. Formação em Direitos Humanos. Corpo docente. Capacitação de Professores.

\section{ABSTRACT \\ WHO TRAINS CIVIL POLICE OFFICERS IN HUMAN RIGHTS? A LOOK AT THE ACADEMY OF THE CIVIL POLICE OF SÃO PAULO}

The programme of the subject "Human Rights: Civil Police and Diversity", taught in the training courses of the Civil Police Academy of São Paulo, has undergone a series of changes over the years, especially focused on the introduction of themes such as gender, race, sexual diversity and disability. Based on these reformulations, this article seeks to analyze the faculty responsible for this subject as well as whether they received initial or continuing training to deal with the new issues. To this end, we sought to identify the selection processes of teachers, as well as whether there were teacher qualification programs developed by the unit. The 
methodological path was based on bibliographical research, with attention to the literature on police training and the faculty; documentary, especially publications in the Official State Gazette and legislation about the Police Academy, and also participant observation. The investigation revealed that the field occupies little space in discussions about police training in specialized literature and in the Police Academy itself, with few qualification initiatives for its teachers, which can hinder the effective implementation of the pedagogical proposal presented in the programme of the subject.

Keywords: Civil Police of São Paulo. Police Academy. Human Rights Training. Faculty. Teacher Training.

Data de recebimento: 01/05/2021 - Data de aprovação: 06/09/2021

DOI: 10.31060/rbsp.2022.v16.n1.1523

\section{INTRODUÇÃO}

Este artigo surge como resultado de questionamentos decorrentes de uma dissertação de mestrado sobre a formação dos policiais civis em direitos humanos, com especial enfoque sobre certos grupos em situação de vulnerabilidade, na Academia da Polícia Civil de São Paulo (Acadepol) (MOTA, 2017). Nesse trabalho, foram analisados os conteúdos programáticos de 2008 e 2016 da disciplina atualmente denominada "Direitos Humanos: Polícia Civil e a Diversidade", ministrada a todas as carreiras policiais durante o curso de formação técnico-profissional. A análise cotejou os conteúdos com a Matriz Curricular da Secretaria Nacional de Segurança Pública (BRASIL, 2014), examinou as alterações dos programas, problematizou ausências temáticas e apresentou perspectivas de ensino a partir da compreensão da vulnerabilidade como elemento que determina a forma de interação entre indivíduos e policiais civis. Constatou-se que, apesar de ainda priorizarem questões teóricas e pouco práticas e críticas, os conteúdos vêm sendo alterados de forma positiva, com a inclusão de pontos relacionados a gênero, raça, diversidade sexual e deficiência.

Diante desse universo analítico surgiu o interesse em investigar, particularmente, a figura do responsável por lecionar essas aulas, pois se os conteúdos avançavam em termos de maior inclusão dos coletivos em situação de vulnerabilidade e das discussões a respeito de sua relação com a atividade policial, será que o corpo docente estava acompanhando essas reformulações? E tais reformulações, importante destacar, tanto do ponto de vista do acréscimo de conteúdo, como novos conceitos, atos normativos, legislação e discussões doutrinárias e jurisprudenciais, quanto em relação ao aperfeiçoamento das metodologias de ensino para abordar tais temas, considerando as especificidades e finalidades dessa formação profissional.

Para que fosse possível identificar o lugar que o professor ocupa nesse processo de mediação do conhecimento ante as modificações dos programas, foi necessário estabelecer duas questões prévias: 1) Como a Acadepol seleciona os professores da disciplina Direitos Humanos? e 2) Esse corpo docente recebe algum tipo de formação inicial ou capacitação técnica e pedagógica para que esteja alinhado às alterações dos conteúdos programáticos?

O caminho percorrido para buscar as respostas a tais perguntas apontou em muitas direções e possibilidades de pesquisas, que indicaram a necessidade de maior atenção sobre o corpo docente responsável pela formação dos policiais. Este trabalho, assim, pretende contribuir para as pesquisas sobre ensino policial a partir de um sujeito específico e ainda pouco abordado na produção científica sobre o tema: o policialprofessor, figura sem a qual, ainda que existam ações formativas sobre direitos humanos capazes de aperfeiçoar o trabalho policial, esse processo estará incompleto, na medida em que os docentes não terão ferramentas adequadas para alcançar as expectativas dos programas e da instituição. 


\section{METODOLOGIA}

O ponto de partida do percurso metodológico, que se assentou na pesquisa qualitativa, foi o levantamento bibliográfico sobre a formação policial com ênfase no corpo docente das academias de polícia civis, no entanto foram localizados poucos trabalhos. Como forma de complementar esta lacuna, também foi feito levantamento bibliográfico sobre a formação do professor do ensino superior e a profissionalização da docência. Por se tratar da educação de adultos, muitas similaridades foram encontradas e o debate produzido nessa área pode contribuir para o campo do ensino policial.

Outra estratégia empreendida foi a pesquisa documental. Tendo como elemento do trabalho a formação em direitos humanos dos policiais civis e com o objetivo de estabelecer o conteúdo com o qual o corpo docente dialoga, foram examinados quatro programas da disciplina Direitos Humanos. Considerando as finalidades deste artigo, mais do que um estudo detalhado sobre cada item, a análise centrou-se na inserção de conteúdos relativos aos grupos em situação de vulnerabilidade que pudessem exigir competências específicas dos docentes para que dessem conta das demandas do programa e das eventuais dificuldades que poderiam surgir em sala de aula para a abordagem dos novos pontos.

Como na Academia de Polícia há processo seletivo para o cargo de professor, também foi feita pesquisa documental para verificar se havia editais para professor de Direitos Humanos e publicações de cursos relacionados com a capacitação do corpo docente de um modo geral. Tais documentos são atos oficias e públicos, de modo que o levantamento foi realizado no site do Diário Oficial do Estado de São Paulo, na Secretaria de Cursos de Formação ${ }^{1}$ e na Secretaria de Cursos Complementares, de Pesquisa e Apoio à Produção Científica² da Acadepol.

A pesquisa também se debruçou sobre a legislação relativa à Academia de Polícia: o Decreto № 60.930/2014, que reorganizou o departamento, e a Resolução SSP-104, de 5 de julho de 1983, e suas alterações, que aprovou o Regulamento da Academia de Polícia (RAP). O objetivo, nesse caso, foi localizar menções à figura do professor ou à institucionalização de sua atividade no centro de ensino da Polícia Civil de São Paulo.

Por fim, também foi empregada a observação participante, realizada entre março de 2019 e março de 2020 na Academia da Polícia Civil de São Paulo. Adotada de forma combinada e integrada com o levantamento bibliográfico e a pesquisa documental, a observação participante possibilitou não só o contato com a diretoria, os professores e os funcionários, mas também a pesquisa e o acesso aos documentos que não foram localizados no Diário Oficial, como dados sobre o corpo docente, programas de cursos, propostas para atividades acadêmicas e informações sobre eventos realizados. Além disso, possibilitou a observação das práticas dos professores de direitos humanos, suas expectativas e dificuldades com a implementação dos novos conteúdos e a elaboração de material didático para a disciplina. A imersão no campo, bem como a observação e a interação com os sujeitos, permitiu que a pesquisadora se aproximasse da rotina de uma academia de polícia e pudesse compreender sua lógica de funcionamento e as engrenagens que movem a relação do corpo docente com a instituição de ensino ao qual está vinculado (LUPETTI BAPTISTA, 2017).

1 Secretaria responsável por planejar, controlar e executar as atividades dos cursos de formação, direcionados aos novos policiais (art. $8^{\circ}$ do Decreto No60.930/2014).

2 Secretaria que tem por atribuições, entre outras, planejar e executar as atividades dos cursos complementares, de aperfeiçoamento, aprimoramento, atualização, especialização, ou seja, para os policiais que já estão na ativa (Op. cit., art. 9º). 


\section{O LUGAR DA DOCÊNCIA NA FORMAÇÃO POLICIAL}

Embora a formação policial civil e militar seja um tema recorrente na literatura (LARINI, 2020; UEDA, 2020; VEIGA; SOUZA, 2018; BRASIL; FBSP, 2013; BASTOS, 2008; PIRES, 2008; PONCIONI, 2014; 2007; 2005) e nas discussões para além do âmbito acadêmico sobre segurança pública, o olhar sobre a figura docente e sua qualificação nas academias de polícia ainda é insuficientemente explorado e isso se reflete nos poucos e esparsos trabalhos encontrados, dentre os quais a maior parte é dedicada ao corpo docente da Polícia Militar (DANTAS, 2019; MELO; CARVALHO, 2019; PEREIRA; CRUZ, 2017; NASCIMENTO; CERQUEIRA, 2015; VERAS, 2008).

Se na literatura especializada predomina a escassez de estudos sobre a docência nas academias de polícia, na Matriz Curricular da Senasp (2014) é possível encontrar menções sobre o papel do professor e orientações sobre estratégias didáticas. Tais considerações, entretanto, priorizam sua importância como peça-chave no processo de ensino-aprendizagem. Nesse sentido, o investimento em sua formação e qualificação e o estímulo à participação em programas de pós-graduação chegam a ser citados como iniciativas que devem ser consideradas no planejamento e na execução das ações formativas, no entanto não se apresenta uma discussão aprofundada sobre os impactos da capacitação na qualidade do ensino ou, ainda, uma reflexão crítica sobre as competências específicas do policial-professor.

Seja na academia, seja nos documentos oficiais, a desatenção ao exercício da docência policial, bem como a ausência de discussões sobre as estratégias para a capacitação de docentes, pode ter como uma das hipóteses a noção de "quem sabe fazer sabe ensinar" (CUNHA, 2008, p. 10). Essa compreensão vincula-se à ideia do profissional como detentor absoluto das competências e habilidades necessárias para preparar os alunos para o exercício da função, ou seja, por se tratar de um ensino profissionalizante, os saberes adquiridos no mundo do trabalho seriam suficientes para habilitar os professores para a formação de seus pares, sem que houvesse necessidade de capacitação específica para a docência ou apreensão de conhecimentos pedagógicos.

Outro ponto relevante sobre a formação policial é o que diz respeito àquilo que se espera de seus resultados e o papel que lhe corresponde para que os agentes de segurança púbica executem seu trabalho de maneira uniforme e profissional, segundo as exigências constitucionais. Ainda que a educação e o treinamento - e aqui incluída a atividade docente - sejam importantes instrumentos para que as polícias atinjam padrões de excelência pautados nos parâmetros de uma sociedade democrática (PONCIONI, 2014), tal ensino, com destaque para os direitos humanos, e o investimento no corpo docente não garantem, por si só, o cumprimento dessa expectativa. Há, assim, uma relativização dos efeitos pretendidos e produzidos durante a formação, pois outros fatores entrarão em jogo para a construção da identidade profissional (BRESSOUX, 2003).

Nesse sentido, os processos de socialização do policial, especialmente após a formação e o início do exercício de suas funções, também moldarão sua atuação e a forma como concebe e exerce o seu trabalho. Como aponta Cunha (2004), a imersão na cultura profissional, que compreende não só conhecimentos específicos, mas também uma visão de mundo particular, constrói uma nova identidade e a partir daí o policial vê e interage com o mundo segundo essa perspectiva. O cotidiano policial brasileiro, com persistentes e elevados índices de violência e violações de direitos humanos praticados por seus agentes (FBSP, 2020a; SINHORETTO; SILVESTRE; SCHLITTLER, 2014; CARDIA, 2012), proporcionará uma outra forma de aprendizagem, na qual o sistema de práticas forjado no exercício da função pode incorporar ou 
reforçar esses aspectos, comprometendo a formação dada nas academias de polícia. Por tal motivo, ainda que a formação inicial e continuada dos policiais seja imprescindível para a qualidade do trabalho, ela deve ser considerada em conjunto com outros fatores que também terão importância quando se analisa o atual quadro da segurança pública no Brasil.

O último ponto que deve ser abordado nesta seção é a relação entre a construção de uma nova disciplina e o corpo docente encarregado de ministrá-la. Inserir uma nova disciplina na grade curricular de um curso, especialmente a respeito de um assunto imprescindível para as instituições policiais e que até hoje pode encontrar resistência para ser abordado, socialmente ou entre os próprios integrantes do sistema de segurança pública, demanda uma série de ações pedagógicas que se iniciam antes mesmo de o professor ministrar as aulas. Essas medidas consistem, por exemplo, na aprovação pelas instâncias escolares superiores; na criação de um plano de ensino, com conteúdo programático, sistema de avaliação e bibliografia básica; na preparação do material didático; na articulação com outras disciplinas e na qualificação do corpo docente para que esteja alinhado com os objetivos desejados pela instituição. As medidas, portanto, não se centram apenas na criação do conteúdo da disciplina; mais do que isso envolvem, ativamente, vários sujeitos do contexto escolar, como os professores e a Secretaria de Cursos de Formação.

O primeiro contato com o tema sob a ótica profissional, além disso, requer que se estabeleça, desde um ponto de vista institucional, o que se pretende com a introdução da nova disciplina e, no caso do ensino de direitos humanos, isso envolve não só conhecimento jurídico e compreensão sobre o trabalho policial segundo parâmetros nacionais e internacionais, mas, especialmente, a reflexão sobre o papel desses agentes como produto e produtores do sistema de relações no qual estão inseridos; papel, vale salientar, que não é exercido de forma neutra (CAÇAPAVA, 2012). Mais uma vez, a participação ativa do corpo docente é fundamental nesse processo, não só com aqueles que serão os responsáveis pela disciplina, articulando o saber teórico com o saber profissional, mas também com o processo de construção do programa como resultado de uma atividade colaborativa e comprometida com as finalidades formativas. Como sujeitos do processo de ensino-aprendizagem, os professores também têm a oportunidade de medir a receptividade dos alunos a respeito de temas como gênero, raça e sexualidade, avaliar o que funciona e as formas mais eficazes para abordar as questões, podendo propor ajustes e alterações no programa.

\section{O ENSINO DE DIREITOS HUMANOS NA ACADEPOL}

Para contextualizar o espaço em que interagem os professores da área, é necessário traçar um breve panorama sobre a organização escolar da Academia de Polícia, pois suas características impactam na execução do programa de Direitos Humanos. Além disso, é importante estabelecer como esse tema foi reconhecido como disciplina e as mudanças feitas nos programas ao longo do tempo.

De acordo com o art. $2^{\circ}$ do Regulamento da Academia de Polícia (RAP), integram sua estrutura seis unidades docentes: Administração Policial, Criminalística, Criminologia, Medicina Legal, Polícia Administrativa e Polícia Judiciária. Cada unidade concentra uma série de disciplinas organizadas por afinidade temática ou grande área de conhecimento. A disciplina Direitos Humanos faz parte da unidade de Polícia Judiciária, que abrange todas as temáticas diretamente relacionadas à atribuição constitucional da Polícia Civil.

Cabe às unidades docentes selecionar as disciplinas, a carga horária e o conteúdo programático dos cursos de formação (art. 24 do RAP); autorizar conferências e atividades externas (art. 78, III, do RAP); 
indicar professores de uma disciplina para lecionarem em outras (art. 86 do RAP); propor o número de docentes para cada disciplina e a instauração de processo seletivo para professor (art. $4^{\circ} \mathrm{e}$ art. $5^{\circ}, \S 2^{\circ}$, das Disposições Finais e Transitórias do RAP, respectivamente). Pelas atribuições apresentadas, as unidades docentes e seus dirigentes (assim chamados no Regulamento) teriam grande proximidade com a atividade docente e com o quadro de professores, em um cenário em que todos os sujeitos estariam entrosados para a efetivação das ações formativas.

Convém ter em vista, entretanto, que se a forma como estão organizadas as unidades docentes assemelhase às instituições de ensino superior, com unidades específicas para coordenar o ensino das diversas áreas de conhecimentos essenciais para a formação e congregar os professores das disciplinas afins, a escolha de seus responsáveis se afasta da lógica escolar e privilegia a hierarquia policial. Assim, o coordenador será, preferencialmente, o policial-professor ocupante de cargo da classe mais elevada dentro da respectiva unidade, designado pelo Delegado Geral de Polícia (art. $5^{\circ}$ do RAP). Na impossibilidade, poderá ser designado ocupante de cargo de nível universitário (art. 19 das Disposições Finais e Transitórias do RAP). Chama a atenção o fato de não haver qualquer menção à titulação acadêmica, à experiência na docência e na pesquisa ou em gestão escolar para a seleção do dirigente; os requisitos estão estritamente vinculados à carreira policial.

Ainda sobre a estrutura da escola, é preciso mencionar os delegados divisionários de polícia, responsáveis pela administração das secretarias da Acadepol. A escolha para tais cargos é feita pelo diretor da instituição e fica a seu critério considerar eventual formação pedagógica, titulação acadêmica ou experiência em gestão escolar como requisitos para a seleção. A este respeito, não há qualquer normativa e, com algumas exceções, esse não foi um aspecto levado em conta para a escolha dos gestores. Essa sistemática também se aplica à escolha do diretor da Acadepol, que para ocupar o cargo não the é exigida qualquer experiência na docência, nem conhecimentos em gestão escolar ou titulação acadêmica.

Como resultado desse cenário, a lógica policial se sobrepõe à lógica educativa e impacta no plano concreto do cotidiano escolar, especialmente por não priorizar aspectos acadêmicos e pedagógicos, mas policiais, e o exemplo acima mencionado sobre a escolha dos dirigentes das unidades docentes exemplifica essa afirmação. Nesse sentido, é fundamental ter em conta que as necessidades de um departamento de polícia não são as mesmas de uma escola de ensino profissionalizante. No caso das academias de polícia, essas necessidades se confundem, no entanto a prioridade recai sobre as primeiras. Por se tratar de formas de interação distintas, não há espaço para investimentos humanos e materiais nos campos que envolvem a educação: formação e capacitação de professores, recursos para o aprendizado, bibliotecas, laboratórios, sistemas de avaliação da qualidade do ensino, organização de eventos e fomento aos programas de pesquisa para a construção de doutrina policial, por exemplo. Embora exista um sistema de organização formal amparado por textos normativos, a observação metodológica empreendida nesta pesquisa permitiu constatar que, em termos práticos, há pouca constância na dimensão educacional, dependendo seu maior ou menor grau, principalmente, das pessoas que ocupam os cargos de liderança do departamento. Se são policiais que têm experiência acadêmica fora da instituiç̧ão ou que compreendam as funções da Acadepol como relacionadas, primordialmente, ao ensino e à pesquisa, as ações formativas se intensificarão. Do contrário, os projetos pedagógicos e as redes que sustentam a dimensão educacional se fragilizarão.

Essas observações servem como pano de fundo para compreender como o programa de Direitos Humanos da Acadepol se desenvolve. Nesse caso, além da unidade docente de Polícia Judiciária, a disciplina também 
tem ligação com o Centro de Direitos Humanos e Segurança Pública "Celso Vilhena Vieira" (CDHPC)³, cujos integrantes elaboram os conteúdos programáticos e ministram aulas sobre direitos humanos. Apesar dessa afinidade formal, não há, de fato, uma interação entre o dirigente da unidade, os integrantes do centro e os demais professores para a discussão das estratégias para o ensino de direitos humanos na Acadepol, o que pode gerar certa dissonância entre os objetivos pretendidos e o que, efetivamente, ocorre em sala de aula.

A criação do CDHPC coincide com a implementação do ensino de direitos humanos como disciplina própria e componente transversal no currículo dos cursos de formação, sendo a Acadepol, em 1997, a primeira escola de polícia a inserir essa temática em sua grade curricular, não sem encontrar resistência dos policiais (BARALDI, 2012). Desde então, a discussão sobre direitos humanos e segurança pública passou a fazer parte do cotidiano escolar não só dos policiais que iniciavam sua formação, nas carreiras correspondentes aos níveis superior ${ }^{4}$ e médio ${ }^{5}$, mas também daqueles que já estavam na ativa e realizavam cursos de aperfeiçoamento, um dos critérios para a promoção na carreira.

No caso do ensino de direitos humanos, é importante ter em mente que, embora o eixo temático seja comum a todos os cursos, há a necessidade de adaptar o seu conteúdo às atribuições de cada carreira, para que seja dotado de sentido e significado prático para os novos policiais. Dessa forma, se no curso de formação para escrivão de polícia devem ser enfatizados aspectos como a linguagem e o modo de se construir uma narrativa nos documentos oficiais de acordo com o paradigma dos direitos humanos, sem o uso de expressões discriminatórias, depreciativas ou ofensivas; no curso para investigador de polícia, profissionais que em um plantão policial normalmente são os encarregados do primeiro atendimento ao público, é importante destacar noções sobre acolhimento, rede de apoio, violência institucional e revitimização. Diferentes tipos de métodos, recursos e abordagens, portanto, podem ser utilizados, o que exige uma constante atualização e reflexão sobre a prática pedagógica, bem como comunicação entre os professores e a direção, para que essa prática esteja conectada com a realidade e dialogue com outros componentes curriculares ${ }^{6}$.

A necessidade de ajustes nos conteúdos programáticos conforme a carreira foi percebida na fala de alguns professores, no entanto até o presente momento existe apenas um conteúdo programático, que é aplicado a todas as carreiras. Cada professor, então, pode fazer, a partir do material fornecido, os ajustes necessários de acordo com as atribuições específicas de cada turma, destacando certos pontos, passando superficialmente por outros ou exemplificando os tópicos do programa com casos práticos que envolvem as funções daquela carreira.

Passando para os programas de direitos humanos, desde 1997 foram localizados quatro documentos nos quais é possível acompanhar a evolução em relação à carga horária e aos conteúdos. Como não há uma sistematização para o acompanhamento desse processo, não foi possível, no decorrer desta pesquisa, saber ao certo quantos programas existiram ou quantas alterações foram feitas.

3 O CDHPC, criado em 1997, foi regulamentado pela Portaria DGP-01, de 4-2-2013 e pelo Decreto No 60.930/2014. Entre suas atribuições está o auxílio na educação e conscientização dos policiais civis alunos.

4 São elas: delegado de polícia, escrivão de polícia, investigador de polícia, médico legista e perito criminal.

5 São elas: agente policial, papiloscopista policial, auxiliar de papiloscopista policial, agente de telecomunicações policial, auxiliar de necropsia, atendente de necrotério policial, desenhista técnico-pericial e fotógrafo técnico-pericial.

6 Um exemplo desse diálogo é o que ocorre na disciplina Conduta Policial e Técnicas de Abordagem, na qual, a partir dos conceitos trabalhados nas aulas de Direitos Humanos: Polícia Civil e a Diversidade, os alunos aprendem os procedimentos de abordagem e busca pessoal em pessoas com deficiência e pessoas transexuais. Nesse caso, houve uma interação entre os professores, o que produziu uma padronização e um diálogo entre as disciplinas. 
O primeiro deles (MOTA, 2017), de 2008, com carga horária de 12 horas-aula, das quais as duas últimas eram para avaliação, estava centrado em documentos internacionais e nacionais de proteção aos direitos humanos, questões constitucionais sobre atividade policial, violência e uso legítimo da força. O que chama atenção nesse programa, além do conteúdo baseado em aspectos normativos-legais e pouco direcionado ao que os alunos encontrariam no exercício de suas atividades, é a menção aos tipos e às formas de violência, ao uso da força e ao combate à criminalidade, de modo a reafirmar a ideia do papel de manutenção da ordem como trabalho primordial das instituições policiais (PONCIONI, 2007). No caso do uso da força, a abordagem refere-se ao seu uso legítimo, mas não ao excesso e às suas consequências jurídicas, funcionais e sociais (MOTA, 2017). Seguindo esse conteúdo, os professores tinham poucas possibilidades de abordar questões críticas sobre o trabalho policial ou a respeito de grupos que merecem uma atenção maior do Estado por se encontrarem em situação de vulnerabilidade. E se o fizessem, tratavase mais de uma decisão pessoal do que de uma postura institucional.

Outro ponto que merece ser registrado é que o programa de 2008 não apresentava bibliografia básica, o que deixava os professores livres para trabalharem com o material que considerassem mais apropriado. A ausência de bibliografia aponta para uma falta de orientação sobre o que pretende a instituição de ensino quando forma os seus alunos em direitos humanos, já que a seleção bibliográfica revela os fundamentos teóricos e conceituais do programa e auxilia os professores no caminho a ser percorrido na ação formativa.

O segundo programa, inserido na grade curricular das carreiras de escrivão e investigador de polícia em 2010, permaneceu com os mesmos tópicos do anterior, que correspondiam ao denominado "Módulo IParte Geral". A modificação, nesse caso, foi a inserção do "Módulo II: Diversidade Étnico-Racial", com 4 horas-aula e orientado aos seguintes pontos: raça, etnia, racismo, preconceito e discriminação, diferenças entre igualdade formal e igualdade material, diferenças entre crimes de racismo e de injúria racial, racismo na sociedade e racismo policial (CAÇAPAVA, 2012). A carga horária, desse modo, passou de 12 para 16 horas-aula. A abordagem do racismo policial indica um posicionamento crítico sobre a atividade de segurança pública e os temas permitem discussões sob diferentes perspectivas, porém não foram encontradas pistas sobre como tal conteúdo era ministrado ou se os professores o abordavam desde as causas estruturais e institucionais do racismo. Como no primeiro programa, esse também não apresentava bibliografia, o que dificultou a investigação da base teórica para a elaboração do novo módulo ou do suporte para o desenvolvimento das aulas.

A partir de 2016 é possível observar mudanças significativas no conteúdo denominado Direitos Humanos: Polícia Civil e a Diversidade (MOTA, 2017). Além do aumento da carga horária - 24 horas-aula -, mantendose as duas últimas para a avaliação, foram inseridos novos temas, com destaque para orientação sexual, identidade de gênero, estereótipos de masculinidade e feminilidade, crimes de ódio, pessoas com deficiência e a permanência das questões raciais, com realce para uma atividade denominada "Prática Jurídica de Combate ao Racismo"7. A diversidade, assim, para além do complemento ao título da disciplina, também aparecia no conteúdo programático, trazendo desafios ao corpo docente, que deveria estar familiarizado com os novos eixos temáticos e com a proposta didática inclusiva.

Embora seja um programa inovador, especialmente sob a ótica da discussão sobre marcadores sociais da diferença específicos, como nos anteriores, não há menção a qualquer referência bibliográfica ou orientações sobre os objetivos e as diretrizes para a realização da prática de combate ao racismo.

$7 \quad$ Talvez os docentes fossem informados sobre os aspectos que envolviam essa prática diretamente pela Secretaria de Cursos de Formação ou pelos professores que revisaram o programa, porém nada nesse sentido foi apurado durante esta pesquisa. 
Permanece, também, o caráter teórico e pouco prático do conteúdo, ainda com enfoque em fundamentos históricos e filosóficos dos direitos humanos, documentos internacionais e aspectos constitucionais (MOTA, 2017).

O quarto e atual programa, fornecido pela Secretaria de Cursos de Formação, foi reformulado em 2020 e nele também há interessantes alterações, especialmente no que diz respeito ao aprofundamento das questões relativas a gênero, diversidade sexual e raça. A carga horária passou de 24 para 26 horasaula e os blocos temáticos iniciais, teóricos e normativos foram reduzidos para que houvesse espaço para outros tópicos, sobretudo questões práticas que os alunos pudessem se deparar no exercício da função. O programa, mais consistente do que os anteriores, mantém a parte introdutória sobre pontos normativos, conceituais e direito internacional, e para cada grupo em situação de vulnerabilidade ${ }^{8}$ faz um aprofundamento teórico, vinculando-o com a prática. São exemplos das inovações do conteúdo a abordagem sobre: a teoria da interseccionalidade para discutir a violência de gênero e sua aplicação às dinâmicas de opressão e discriminação dos grupos selecionados, a discriminação racial no sistema de justiça criminal, o reflexo da discriminação racial na atividade policial, o tratamento jurídico e nominal às pessoas transexuais e a criminalização da LGBTIfobia.

Acompanha tal conteúdo uma vasta relação de referências que indica qual foi o marco teórico sobre o qual está assentado, além de sugestões de material audiovisual dividido por temas e disponível online. Os docentes que irão ministrar tal disciplina, assim, podem se valer dessas informações não só para o aperfeiçoamento profissional, mas também para a adoção de diferentes estratégias didáticas que podem abrir espaço para discussões mais reflexivas e proporcionar maior engajamento dos alunos a respeito dos direitos humanos.

Ainda que as indicações bibliográficas e de material audiovisual possam ser utilizadas para potencializar a prática docente, mudanças substanciais nos conteúdos também reclamam um conjunto de ações institucionais coordenadas com o corpo docente, para que este esteja alinhado aos fundamentos e objetivos do novo programa. Essas ações envolvem não só o aprimoramento dos saberes teóricos e didáticos dos professores, realizados por meio de atividades de capacitação, mas também a possibilidade de se corresponsabilizarem pela construção dos conteúdos e do material utilizado em sala de aula. Sobre o segundo ponto, as reuniões pedagógicas antes, durante e depois da implementação do novo programa de conteúdo são imprescindíveis para que o corpo docente se veja implicado nesse processo.

Como nas demais disciplinas da grade curricular dos cursos de 2019/2020 da Acadepol, as ações relativas ao atual programa de direitos humanos foram esparsas e descontínuas. Desde a sua implementação, para fins de padronização, os professores devem utilizar em sala de aula material elaborado pelo CDHPC $^{9}$. Com exceção daqueles que integram o centro e quatro professores colaboradores, os demais docentes que ministraram a disciplina durante o período da observação não participaram da construção desse material. Também não houve nenhuma divulgação prévia ou espaço para que houvesse um debate entre todo o corpo docente da disciplina. Como se verá adiante, a ausência de interação entre

8 A pesquisa em campo possibilitou apurar que a seleção dos grupos ocorreu a partir de uma decisão institucional, considerando aqueles que já constavam em programas anteriores (como os relacionados ao gênero e à raça), ou em que a Polícia Civil já tivesse um histórico na institucionalização da proteção de direitos (como no caso das pessoas com deficiência, pois São Paulo foi o primeiro estado a ter uma delegacia especializada) ou em razão da visibilidade e da necessidade de reconhecimento e proteção dos direitos de seus integrantes (como em relação ao coletivo vinculado à diversidade sexual).

9 O material consiste em um conjunto de slides que seguem a ordem do conteúdo programático e destacam os pontos que devem ser abordados em sala de aula. 
os distintos sujeitos envolvidos no processo trouxe dificuldades para aqueles professores que não estavam familiarizados com certos pontos teóricos do programa ou que não se sentiam atualizados em relação às suas habilidades didáticas.

\section{O CORPO DOCENTE DA ACADEPOL}

O quadro de professores da disciplina Direitos Humanos integra a estrutura da Acadepol e, para que se possa investigar quem é essa figura, é preciso analisar como seu corpo docente, de modo geral, é constituído, quais são suas características e a posição que ocupa na organização institucional.

De acordo com Baraldi (2012), a natureza profissionalizante do ensino policial faz com que seu corpo docente seja captado no próprio meio profissional, característica que o define e se reflete na dinâmica que pautará as relações com as instâncias superiores acadêmicas. No caso da Acadepol, o processo de captação e seleção dos docentes ocorre por meio de processo seletivo ${ }^{10}$ (art. 4º, VIII, do Decreto No 60.930/2014) e, com exceção das disciplinas eminentemente policiais, todos os servidores da Administração Pública direta do Estado de São Paulo podem concorrer às vagas. De fato, no quadro de professores da Acadepol há juízes de direito, promotores de justiça, professores da rede pública estadual e policiais militares, o que contribui para outras perspectivas sobre a segurança pública e a atividade policial e possibilita a troca de experiências entre os profissionais de diversas áreas.

Outras exigências para a inscrição no processo seletivo centram-se em aspectos objetivos, como ausência de penalidades funcionais e apresentação de diploma de curso superior de bacharelado ou licenciatura, com poucas menções à formação ou ao conhecimento em pedagogia ou didática do ensino superior. Vale observar, ainda, que não há uma regularidade na publicação dos editais, tratando-se de uma decisão política da direção diante da necessidade de professores de uma certa disciplina ou da inclusão de uma nova na grande curricular.

Como ocorre com os concursos públicos da Polícia Civil de São Paulo, não há um planejamento sobre quando serão instaurados esses processos, qual disciplina ou qual número necessário de vagas para suprir determinada demanda. Tampouco há uma correspondência entre a realização de concursos públicos e a atualização do corpo docente. De fato, esta pesquisa permitiu verificar que enquanto algumas disciplinas têm um número considerável de professores, outras apresentam um grande déficit, o que traz uma série de dificuldades para a execução do cronograma escolar e a organização das aulas quando a Academia de Polícia recebe uma grande quantidade de alunos. Da mesma forma, constatou-se que a maior parte dos docentes não está vinculada apenas à disciplina de aprovação no processo seletivo. É comum que os professores ministrem aulas de acordo com a carreira policial, expertise ou formação na área, sendo considerados, para tanto, cursos de especialização, mestrado e doutorado. Um professor, portanto, pode ser responsável por mais de uma disciplina no mesmo curso de formação, ficando essa distribuição e atribuição de aulas a critério da Secretaria de Curso de Formação.

Ainda que haja integrantes de outras instituições em seus quadros, o corpo docente é composto, majoritariamente, por policiais civis que exercem suas funções em outros departamentos. Além dos cursos de formação, os professores também podem lecionar nos cursos da Secretaria de Coordenação

10 No RAP, o art. $1^{\circ}$, IV, já destacava como uma das funções da Acadepol a realização de concurso para seleção de professor. 
e Controle do Interior ${ }^{11}$, na Secretaria de Cursos Complementares, de Pesquisa e Apoio à Produção Científica ${ }^{12}$ e participar de outras atividades, como grupos de estudos, dinâmicas, exercícios práticos, palestras, comissões de concursos públicos e processo seletivo para professores ${ }^{13}$. Também podem ser convidados para elaboração e revisão de material didático, organização de seminários, elaboração de diretrizes acadêmicas, reuniões pedagógicas e assessoramento ao diretor em atividades acadêmicas.

Como são policiais que exercem suas funções em outras unidades, a atividade docente não é exclusiva e contínua, sendo exercida conforme a demanda dos cursos e outras atividades. É importante observar que mesmo os professores que, eventualmente, estão lotados na Academia de Polícia exercem outras funções, sendo a docência uma atividade secundária, eventual e remunerada.

O fato de não haver dedicação exclusiva pode gerar dificuldades para os policiais-professores, pois, para que possam lecionar, devem deixar seu ambiente de trabalho e negociar a ausência com seus superiores hierárquicos, compensando as horas posteriormente ${ }^{14}$. Outro ponto que merece destaque é que, em razão da natureza da atividade policial, os policiais-professores podem ter imprevistos durante sua jornada de trabalho e as aulas, previamente agendadas, podem ser prejudicadas pela impossibilidade de comparecimento à Acadepol.

Larini aponta outro problema que surge em razão da falta de dedicação exclusiva:

[...] a ausência de um corpo docente com total dedicação ao desenvolvimento das atividades de ensino tem consequência imediata, em razão dos vários encargos e determinações que são derivadas do nível superior, causando, assim, danos ao desenvolvimento completo dos cursos que são oferecidos pela corporação. Desse modo, profissionais não qualificados para a função de coordenação pedagógica e elaboração dos cursos são colocados nessas funções. (LARINI, 2020, p. 102).

Esse e outros problemas, como as deficiências de recursos humanos para o ensino, a ausência de exclusividade para o exercício das funções nas academias de polícia e a falta de preparo específico para o exercício da docência já foram apontados (BARALDI, 2012; PONCIONI, 2007; SILVA, 2007) e também puderam ser constatados, de forma persistente, na academia de polícia paulista. Esse quadro indica a falta de uma cultura escolar e de uma compreensão de que, ainda que seja um dos departamentos da Polícia Civil de São Paulo, a Acadepol também é uma escola de governo e, como tal, deve seguir, para o sucesso de suas atividades, os parâmetros de estruturação e organização escolar, com pessoal capacitado para essa função.

A falta de cultura escolar, comentada por Baraldi (2012), refere-se a diversos fatores, como desconhecimento das normas educacionais; falta de treinamento para as atividades desempenhadas; ausência de diretrizes ou orientações sobre a rotina escolar para a execução do trabalho; ausência de representação docente, discente ou dos funcionários na Congregação ${ }^{15}$; problemas na elaboração e no

11 Essa secretaria coordena as atividades das Unidades de Ensino e Pesquisa dos Departamentos de Polícia Judiciária de São Paulo Interior (art. $10^{\circ}$ do Decreto $N^{\circ}$ 60.930/2014).

12 Os três cursos de pós-graduação lato sensu oferecidos pela Acadepol (Direitos Humanos e Segurança Pública no Brasil, Polícia Judiciária e Sistema de Justiça Criminal e Medicina Legal e Perícias Médicas) estão vinculados a esta secretaria.

13 A distinção terminológica segue o Decreto No 60.930/2014: concursos públicos para ingresso nas carreiras policiais civis (art. 50, III, b, 1) e processo seletivo para professor (art. 22, 1, a, 2).

14 De acordo com a Portaria Acadepol - 82, de 16-7-2015

15 A Congregação é composta pelo diretor, por delegados divisionários de polícia das secretarias e pelos dirigentes das unidades docentes. Tem como atribuições, entre outras, homologar a constituição das comissões dos concursos públicos e do processo seletivo para professor e deliberar sobre outras decisões das secretarias (art. 22 do Decreto No 60.930/2014). 
seguimento de projetos pedagógicos, planos de ensino e outros documentos e práticas escolares. O trabalho, dessa maneira, é aprendido na prática, em que os funcionários mais experientes ensinam os mais novos. Essa forma de apreender o trabalho também faz com que ele seja realizado intuitivamente ou segundo diretrizes da direção, sem qualquer respaldo pedagógico, e pode mudar repentinamente se houver substituições das pessoas que ocupam os cargos de comando do departamento.

A falta de cultura escolar também se reflete em como a escola lida com o seu corpo docente, com poucas e frágeis ações para o desenvolvimento ou aperfeiçoamento didáticos. A mais consistente foi o Curso de Atualização para Docentes do Ensino Policial (SÃO PAULO, 2007; 2008a), cujos objetivos eram discutir estratégias do ensino policial civil, com atenção para a elaboração de planejamento didático, reflexão sobre ética docente e desenvolvimento de habilidades para as várias técnicas de ensino. O curso ocorreu em 2007 e 2008, porém foi interrompido e, em 2018, retirado do Plano Anual de Ensino, um plano publicado anualmente no Diário Oficial do Estado e que estabelece a relação de cursos que podem ser ministrados durante o ano. Um dado que merece destaque consta na última publicação feita sobre o curso (SÃO PAULO, 2008b), comunicando sua não realização, pois o número de inscritos fora insuficiente. Como o curso não era obrigatório, tal fato poderia explicar, ainda que parcialmente, sua descontinuidade e também sugerir o pouco interesse dos docentes na formação pedagógica, no entanto seriam necessários outros estudos para averiguar a razão pela qual a atividade não teve êxito, considerando não só a percepção dos policiais-professores, mas ainda o contexto e a forma como a instituição de ensino elaborou, apresentou e divulgou o curso.

Ainda que cada professor tenha um projeto didático para as aulas, construído a partir de seus conhecimentos, sua formação acadêmica e eventual experiência no ensino superior, é imprescindível que a unidade escolar se responsabilize pela capacitação de seus docentes e estabeleça programas contínuos e regulares para os professores que acabam de ser aprovados e para aqueles que já têm experiência no magistério policial. A construção de uma política institucional a respeito do tema pode contribuir para que esses projetos perdurem no tempo e não estejam suscetíveis às mudanças políticas ou representem medidas isoladas, como no caso do curso comentado.

Outro ponto importante sobre o corpo de professores é a forma como, depois de aprovados, entram em contato com a dinâmica da Acadepol. Esse é um momento primordial na nova relação que se estabelece entre o policial e a instituição de ensino, marcada por vínculos pautados na docência e não nas atividades de polícia judiciária. Surge, assim, a necessidade de ressignificar o seu fazer profissional, e às funções do policial se somam as de professor. Nesse processo, sua vivência profissional converte-se em ferramenta para sua prática didática. Essa vivência, entretanto, deve estar amparada por formação pedagógica, para que o processo de ensino-aprendizagem e as competências profissionais sejam, de fato, desenvolvidas, e sua experiência não se transforme em narrativa sobre sua vida. Quanto maior for a atenção institucional aos aspectos que envolvem seu corpo docente e quanto mais professores compreenderem, desde o início, as implicações de se comprometerem com a docência como outra profissão e não apenas como ocupação secundária e esporádica, maiores serão as possibilidades de que a formação policial seja consistente e de qualidade.

Desde o ponto de vista institucional, a observação realizada durante esta pesquisa indicou que, apesar da relevância na transição do policial para policial-professor, não há qualquer formalidade para a integração dos novos docentes à escola, com exceção do cadastro no Setor de Atribuição de Aulas, responsável pela remuneração dos profissionais. Como os sistemas das secretarias não estão integrados, os novos 
professores também comunicam seus dados a cada uma delas, para que seus nomes estejam na relação dos docentes disponíveis. Aprovados, os professores são absorvidos pela dinâmica da escola e passam a ser convidados para ministrarem aulas conforme a necessidade, muitas vezes sem conhecerem a estrutura, a organização e as possibilidades de docência na Acadepol ou, ainda, os outros colegas ou os responsáveis pelas instâncias superiores. Como não há uma coordenação pedagógica para centralizar as questões relativas ao processo de ensino-aprendizagem, as interações se estabelecem entre os novos professores e a Secretaria, e os impasses que surgem - dúvidas burocráticas, relacionamento com alunos, questionamentos sobre os conteúdos programáticos e material didático, cronograma e controle das atividades docentes - são resolvidos de formas distintas, segundo as rotinas de cada seção.

\section{QUEM ENSINA DIREITOS HUMANOS NA ACADEPOL?}

Inseridos no contexto apresentado anteriormente, o quadro de professores de Direitos Humanos da Academia de Polícia é composto por policiais civis de diversas carreiras, com predominância dos delegados de polícia. Alguns também lecionam em instituições de ensino superior e, por isso, talvez tenham contato com métodos de ensino e organização escolar. Tal fato, contudo, não garante que esse conhecimento funcione no contexto policial, já que esse ensino apresenta uma série de exigências e particularidades, considerando as atribuições da carreira e os desafios que surgem na execução do trabalho.

Como a realização dos cursos é irregular, o contato dos professores com o centro de ensino não é constante e surge somente quando há necessidade de verificar a disponibilidade para as aulas. O contato é feito pela Secretaria de Cursos de Formação, que, após o aceite do docente, lhe envia o material didático. Eventualmente, também pode ser enviado o conteúdo programático, caso seja um novo programa ou a primeira vez que o professor ministra a disciplina.

Um aspecto que chama a atenção na disciplina é que desde a sua criação até o momento em que foi realizada esta pesquisa, somente dois processos seletivos para a captação de docentes foram instaurados. Antes da seleção específica, professores da disciplina Direitos da Cidadania, na qual os direitos humanos eram abordados, ministravam as aulas (CAÇAPAVA, 2012).

O primeiro certame foi instaurado em 1997 para o preenchimento de dez vagas, com os seguintes requisitos: 1) ser servidor da Administração Pública direta do Estado de São Paulo; 2) ter grau superior em Direito, Psicologia, Ciências Sociais, História, Filosofia ou Serviço Social; e 3) ter bons antecedentes funcionais (SÃO PAULO, 1997). Seguindo a estrutura estabelecida para os processos seletivos, na primeira etapa, os candidatos deveriam apresentar uma monografia, cujo tema foi "Violação de Direitos Humanos: a) extermínio; b) tortura; c) discriminação racial e d) discriminação contra a mulher e respectivos instrumentos de proteção da pessoa humana". Já para a segunda etapa, uma aula-prova, os temas versaram sobre a evolução histórica e filosófica dos direitos humanos, a incorporação dos tratados internacionais de direitos humanos do direito brasileiro, a polícia como instrumento de realização da cidadania e garantia dos direitos humanos e os direitos humanos dos reclusos, com enfoque nas regras mínimas da ONU e seus reflexos na Lei de Execução Penal.

A última etapa, de títulos, previa, expressamente, a concessão de pontos para candidatos com título de pós-graduação, pedagogia ou professor ou, ainda, pelo exercício no magistério policial, o que indica uma preocupação com a formação dos futuros professores, mas uma formação que é anterior ao ingresso 
e, com exceção do último critério, desconectada da docência policial. O edital, ainda, apresentava uma lista de sugestões bibliográficas, o que poderia guiar os candidatos quanto à linha teórica adotada pela comissão do processo seletivo. Nesse processo foram aprovados dez candidatos.

Em 2012, no segundo processo seletivo, com abertura de cinco vagas, o tema da monografia foi "A importância da educação em direitos humanos para as atividades de polícia judiciária". Já para a aulaprova, os temas foram os seguintes: 1) "Direitos humanos - conceito e evolução histórica"; 2) "Direitos humanos e a Comissão da Verdade - Reflexos"; 3) "A atuação da Polícia Civil nos crimes de intolerância sob a ótica dos direitos humanos"; 4) "Direitos humanos na investigação policial"; e 5) "Direitos humanos na prevenção da violência policial" (SÃO PAULO, 2012). O sistema de atribuição de pontos permaneceu o mesmo do edital anterior. Nesse processo foram aprovados três candidatos.

Ambas as seleções mantiveram a mesma estrutura e diversidade temática, exigindo dos candidatos conhecimentos teóricos e práticos sobre os direitos humanos e vinculando-os à atividade policial. Ainda que a dimensão da docência apareça somente no sistema de pontuação dos títulos e não como um requisito fundamental para o candidato, ela também privilegia aqueles que já possuíam conhecimento na área. Desde um ponto de vista formal, portanto, os editais parecem dar conta das exigências para o cargo, no entanto, também é importante verificar qual era, na prática, a dinâmica docente.

Considerando a realização de apenas dois certames, o quadro de docentes não é suficiente para suprir a demanda dos cursos, razão pela qual, ao longo dos anos, foi sendo preenchido por outros professores com conhecimento prático ou formação na área ou, ainda, experiência ministrando tal conteúdo. A disciplina original de parte desses profissionais é Inquérito Policial, porém professores de Criminologia, Investigação Policial, Legislação Penal Especial, Mediação de Conflitos, Polícia Comunitária e Redação Oficial também lecionam a matéria. A princípio, essa diversidade pode ser interessante e permitir uma abordagem interdisciplinar em sala de aula, mas para se chegar a tal constatação seria necessário averiguar se ou como esses professores se relacionam com as estruturas responsáveis pelo ensino de direitos humanos, ou seja, o dirigente da unidade docente de Polícia Judiciária e os integrantes do CDHPC, para que que as pretensões formativas estejam alinhadas e haja um diálogo entre os sujeitos envolvidos nesse processo.

Durante a investigação na Academia de Polícia para este trabalho, estavam em andamento cursos de formação de sete carreiras policiais, de forma que foi possível observar a rotina da escola e conversar com alguns professores sobre as inovações nos programas de Direitos Humanos. Com atenção à implementação do novo programa no curso de delegado de polícia, a percepção foi que, diante da nova proposta, alguns professores chegaram a expressar preocupação e mencionar as dificuldades em ministrar tal conteúdo, pois não estavam familiarizados com certos conceitos ou pontos do programa e, tampouco, tiveram tempo suficiente para se prepararem para as aulas. Como alguns também não participaram da elaboração do material didático, surgiu a preocupação em como planejar a aula a partir de um material em que não pôde contribuir e que, necessariamente, deveria ser utilizado em sala de aula. Um terceiro aspecto observado foi o receio de alguns docentes em enfrentar, com a profundidade que exigia o programa e estava expressa no material didático, as discussões sobre gênero, raça e sexualidade em sala de aula e como lidar com as tensões que daí poderiam surgir com o corpo discente. Um caminho para minimizar essas adversidades seria a integração não somente entre os docentes da disciplina e a Secretaria de Cursos de Formação, que poderiam compartilhar seus anseios, suas dúvidas e expectativas, mas também com o Centro de Direitos Humanos, que serviria como uma referência para apoiar os professores nessa tarefa. Os aspectos apresentados também indicam a necessidade de implementação 
de medidas didáticas planejadas e coordenadas com a reformulação curricular para que os professores se sintam amparados pela instituição de ensino e tenham o repertório necessário para enfrentar os desafios que permeiam o trabalho docente.

Percebe-se, assim, que a evolução em termos de conteúdo e o aumento da carga horária do programa de direitos humanos não foram acompanhados por um incremento no quadro de professores ou na formação continuada para que pudessem refletir sobre os saberes necessários para que os programas fossem, efetivamente, colocados em prática desde uma perspectiva pedagógica.

\section{BOAS PRÁTICAS SOBRE A QUALIFICAÇÃO DE DOCENTES}

O conhecimento e a divulgação de boas práticas no âmbito policial podem ser um interessante instrumento para o reconhecimento e a valorização de atividades, encorajando a identificação de lacunas e a elaboração de projetos para erradicar ou modificar as más práticas (MACAULAY; MARTINS, 2018). Além disso, podem inspirar ou ser aplicadas em outros contextos, contribuindo para o fortalecimento do diálogo interinstitucional entre os órgãos de segurança pública. No âmbito da formação, as boas práticas auxiliam o desenvolvimento de uma cultura escolar nas academias de polícia, reforçam a dimensão pedagógica e permitem que sirvam de parâmetro para outras disciplinas e cursos.

Nesse contexto, ainda que não tenham sido desenvolvidas no âmbito da disciplina Direitos Humanos, duas iniciativas recentes sobre violência de gênero e direcionadas, exclusivamente, aos docentes da Acadepol merecem destaque, pois estão vinculadas ao eixo temático que interessa a esta pesquisa. Outra medida significativa foi a instauração de processo seletivo para professor de Didática do Ensino Superior, o que indica um movimento da instituição para a qualificação pedagógica dos docentes.

A primeira ação foi o seminário Princípios Pedagógicos para a Formação Policial em Violência de Gênero, desenvolvido pelo Fórum Brasileiro de Segurança Pública e realizado em parceria com a Acadepol em julho de 2019 (SÃO PAULO, 2019a). O objetivo foi discutir com os professores que ministravam aulas relacionadas à temática de gênero como trabalhar os mitos e preconceitos em relação à violência doméstica e à violência sexual na formação dos policiais, e apresentar recursos pedagógicos para auxiliá-los nessa tarefa. O evento, mais do que um espaço para abordar questões teóricas, permitiu que os professores refletissem sobre suas práticas e compartilhassem suas experiências e inquietações, avaliando o que havia funcionado, o que deveria ser repensado e o que poderia ser aperfeiçoado em sala de aula (MACAULAY; MARTINS, 2018).

Criar oportunidades como essas, em que uma escola de polícia se abre para outros autores que não pertencem à segurança pública, e organizar ações conjuntas voltadas para os professores impacta de forma positiva na qualidade do processo de ensino-aprendizagem, especialmente das disciplinas vinculadas aos direitos humanos, pois incentiva a adoção de novas abordagens e métodos interativos de ensino, fomenta a aproximação entre os docentes da área e as organizações civis e indica uma preocupação institucional. A prática docente baseada na troca ativa de ideias e experiências, assim, enriquece o repertório dos professores, colabora com sua atualização, cria redes de apoio e favorece a formulação de respostas a problemas concretos, de modo a proporcionar um maior envolvimento e efetivo aprendizado dos alunos, motivando-os a transformar sua prática profissional e refletir criticamente sobre a posição que ocupam perante a realidade como agentes da segurança pública (FBSP, 2020b). 
A segunda iniciativa foi uma ação desenvolvida no âmbito do Programa de Pesquisa e Capacitação Continuada em Feminicídio e a Investigação sob a Perspectiva de Gênero (SILVESTRE, 2019). Entre os objetivos, estava a capacitação dos policiais civis sobre a investigação de mortes violentas de mulheres sob a perspectiva de gênero e a promoção e o fomento de atividades voltadas para a produção e a difusão de conhecimento sobre feminicídios (ACADEPOL, 2018). Como consequência das diretrizes do programa, foi criada a disciplina Feminicídio e a Investigação sob a Perspectiva de Gênero ${ }^{16}$, inserida na grade curricular de todos os cursos de formação.

Como o programa previa uma nova abordagem para o tratamento da questão e isso exigia uma padronização das medidas formativas que seriam adotadas, a nova disciplina mobilizou a direção a investir na qualificação de seus professores que, como no caso anterior, já ministravam aulas que envolviam gênero ${ }^{17}$. O objetivo, nesse caso, era que todos os professores falassem a mesma "linguagem" e estivessem alinhados com o projeto pedagógico.

Em setembro de 2019, então, foi realizado o seminário Feminicídio e a Investigação sob a Perspectiva de Gênero (SÃO PAULO, 2019b; SILVESTRE, 2019), ocasião em que os professores do Grupo de Estudos sobre Mortes Violentas de Mulheres - Feminicídios ${ }^{18}$, responsáveis pela elaboração da disciplina, apresentaram seu conteúdo programático e o material que havia sido produzido sobre o tema (GUEBERT; MOTA, 2019a; 2019b). O objetivo do evento, além da apresentação dos tópicos do programa, centrou-se em estabelecer diretrizes didáticas, conceituais e procedimentais sobre o ensino do feminicídio na Acadepol, de modo que os docentes pudessem desenvolver as habilidades necessárias para ministrar tal conteúdo conforme cada carreira e momento formativo.

A partir dessa capacitação, foi possível criar uma rede de professores, bem como disseminar o conhecimento e ampliar a oferta da disciplina nos cursos de formação, especialmente no interior de São Paulo, pois, até aquele momento, ela era ministrada somente na capital e pelos integrantes do grupo de estudos. O contato entre os policiais-professores também permitiu que pudessem refletir sobre o ensino de gênero para policiais, não só desde uma perspectiva da docência, mas também do ponto de vista da experiência profissional. O encontro, deste modo, permitiu a discussão sobre as melhores estratégias didáticas para abordar gênero, sendo também uma oportunidade para que os docentes compartilhassem ocorrências policiais que poderiam embasar estudos de casos e debatessem posicionamentos jurídicos que afetam a atividade policial e que ainda não estão pacificados ${ }^{19}$.

Finalmente, a instauração de processo seletivo para dez vagas de professor de Didática do Ensino Superior representa um marco na valorização das características formativas da Acadepol e aponta para novas perspectivas no ensino policial desde o lugar que um corpo docente capacitado ocupa nesse processo. Ao contrário de outros processos seletivos, nos requisitos para a inscrição, constava a exigência de título de mestrado ou doutorado. Além disso, o edital privilegiava, por meio de atribuição de maior pontuação na etapa dos títulos, os candidatos que tivessem mestrado ou doutorado na área de educação, especialização em didática do ensino superior ou exercício de magistério em cursos de graduação e/ou pós-graduação em instituição de ensino superior (SÃO PAULO, 2019c).

16 Até então, a abordagem do feminicídio ocorria de maneira esparsa, muitas vezes apenas de forma jurídica, restringindo-se à análise da qualificadora, ou com conteúdo repetitivo, pois, raramente, havia comunicação entre os professores das diferentes disciplinas que abordavam o tema.

17 Nesse caso, além desses professores, foram convidados docentes de Inquérito Policial, Investigação Policial, Perícia Criminal e Medicina Legal, considerando o caráter interdisciplinar da nova disciplina.

18 O grupo de estudos, composto por professores da Acadepol, foi criado para instrumentalizar as ações do programa de pesquisa.

19 Por exemplo, as tensões na sala de aula que surgem do debate sobre a possibilidade de mulheres trans e travestis serem vítimas de feminicídio (UEDA, 2020). 
A monografia exigida como parte da seleção foi intitulada "A docência no ensino superior com ênfase nos cursos de pós-graduação e no ensino policial" e indicava a preocupação tanto com o corpo docente dos cursos de pós-graduação oferecidos pela Academia de Polícia quanto com o conjunto de professores do ensino policial de forma geral. Do mesmo modo, a seleção dos temas da aula-prova, que conciliavam os conhecimentos em didática com as singularidades do ensino policial, como didática do ensino superior e o ensino policial; métodos de ensino para adultos e ensino profissionalizante; metodologias ativas de aprendizagem no ensino superior; e ensino a distância (SÃO PAULO, 2019c).

Um passo importante para o fortalecimento da disciplina, que ainda está em fase inicial, foi a inclusão na Unidade Docente de Administração Policial, o que contribui para a sua manutenção na grade curricular da Acadepol (SÃO PAULO, 2021). Vale pontuar, contudo, que esse fato só será efetivo se as instâncias escolares superiores se apropriarem da disciplina como o principal instrumento para uma reformulação na forma como a dimensão pedagógica é tratada no centro de ensino e alocarem esses professores em pontos estratégicos da formação, aproveitando todos os seus conhecimentos. Desse modo, os docentes aprovados poderão auxiliar não só na organização da rotina escolar, mas também subsidiando um projeto de ações pedagógicas consistentes e contínuas, centrado no desenvolvimento de habilidades específicas, sobretudo a capacidade didática, para o desempenho da atividade docente na Acadepol.

\section{CONSIDERAÇÕES FINAIS}

Diante das inovações curriculares no programa de Direitos Humanos dos cursos de formação da Acadepol, este artigo buscou averiguar se o corpo docente acompanhou essas mudanças, considerando não só aspectos técnicos e jurídicos, mas, especialmente, didáticos. Para tanto, foi necessário estabelecer o lugar da docência na formação policial, um lugar que, embora imprescindível no processo de ensinoaprendizagem, ainda é pouco explorado pela literatura da área e pelas próprias academias de polícia. Desse modo, a forma como se estabelece a dinâmica entre escola, professores, programa e outros aspectos pedagógicos será marcada por descontinuidade, dificuldades práticas e falta de comunicação com as instâncias formalmente responsáveis pelo ensino de direitos humanos.

A fragilidade da dimensão pedagógica na Acadepol, que na relação com seus docentes se acentua, tem como um dos efeitos, a despeito da existência de instrumentos formais que organizem a estrutura escolar, o pouco investimento em ações de capacitação técnica e didática dos professores. Como resultado, percebeu-se que não foram efetivadas medidas para que os docentes acompanhassem os importantes avanços nos conteúdos da disciplina. A completude e o sucesso do projeto pedagógico, assim, dependem de ações que priorizem a formação docente e que sejam prioridade na política educativa da escola.

As iniciativas com ênfase nos professores levantadas durante esta pesquisa apontam para uma possibilidade de reconfiguração da relação entre o quadro docente e a Acadepol e os investimentos na dimensão pedagógica da escola. A criação da disciplina Didática do Ensino Superior reforça esse quadro e abre espaço para o fortalecimento da cultura escolar, na qual esses profissionais, além de ministrarem aulas centradas no desenvolvimento da capacidade docente, poderão auxiliar na reorganização dos processos e das rotinas escolares.

A contribuição que procurou oferecer este artigo pretende reforçar a compreensão do trabalho docente como peça-chave imprescindível para a formação policial e apontar para a exploração desse campo a partir de novas perspectivas, com atenção para o policial-professor. 


\section{REFERÊNCIAS BIBLIOGRÁFICAS}

ACADEPOL - ACADEMIA DE POLÍCIA. Portaria Acadepol 42, em 20 de agosto 2018. Cria o Programa de Pesquisa e Capacitação Continuada dos Policiais Civis do Estado de São Paulo em Feminicídio e a Investigação sob a Perspectiva de Gênero. São Paulo, 20 ago. 2018.

BASTOS, E. A. A formação profissional de policiais de investigação criminal (delegados e detetives): Estudo dos Currículos da Academia da Polícia Civil de Minas Gerais de 1985 a 2002. Dissertação (Mestrado em Educação) - Faculdade de Educação, Universidade Federal de Minas Gerais, Belo Horizonte, 2008.

BRASIL. MINISTÉRIO DA JUSTIÇA. SECRETARIA NACIONAL DE SEGURANÇA PÚBLICA. Matriz Curricular Nacional Para Ações Formativas dos Profissionais da Área de Segurança Pública. Brasília: Secretaria Nacional de Segurança Pública, 2014.

BRASIL. MINISTÉRIO DA JUSTIÇA; FÓRUM BRASILEIRO DE SEGURANÇA PÚBLICA. Mapeamento de modelos de ensino policial e de segurança pública no Brasil. São Paulo: FBSP, 2013.

BARALDI, T. C. A. A formação técnico-profissional do delegado de polícia de São Paulo. Tese (Doutorado em Educação) - Faculdade de Educação, Universidade Estadual Paulista "Júlio de Mesquita Filho", Marília, 2012.

BRESSOUX, P. As pesquisas sobre o efeito-escola e o efeito-professor. Educação em Revista, Belo Horizonte, n. 38, p. 17-89, 2003.

CAÇAPAVA, E. P. da C. A formação do policial civil de São Paulo em direitos humanos: o caso ACADEPOL. Dissertação (Mestrado em Direito) - Faculdade de Direito, Universidade de São Paulo, São Paulo, 2012.

CARDIA, N. (Coord.). Pesquisa nacional, por amostragem domiciliar, sobre atitudes, normas culturais e valores em relação à violação de direitos humanos e violência: Um estudo em 11 capitais de estado. São Paulo: Núcleo de Estudos da Violência da Universidade de São Paulo, 2012.

CUNHA, M. I. da. Inovações pedagógicas: o desafio da reconfiguração de saberes na docência universitária. (Cadernos de Pedagogia Universitária, n. 6). São Paulo: Pró-Reitoria de Graduação, Universidade de São Paulo, set. 2008.

CUNHA, N. V. Como se "fabrica" um policial: algumas considerações em torno dos processos de socialização e formação profissional. Comum, Rio de Janeiro, v. 8, n. 22, p. 198-207, 2004.

DANTAS, G. R. Didática aplicada à segurança pública: um diálogo epistemológico sobre o policial-educador. Revista do Instituto Brasileiro de Segurança Pública, São Paulo, v. 2, n. 4, 2019.

FBSP - FÓRUM BRASILEIRO DE SEGURANÇA PÚBLICA. Anuário Brasileiro de Segurança Pública 2020. São Paulo: FBSP, 2020a.

FBSP - FÓRUM BRASILEIRO DE SEGURANÇA PÚBLICA. Princípios e práticas de formação de policiais para o atendimento às mulheres em situação de violência. São Paulo: FBSP, $2020 b$.

GUEBERT, J. G. V.; MOTA, J. R. G. (Coords.). Feminicídios: Manual de Investigação de Mortes Violentas de Mulheres sob a Perspectiva de Gênero. São Paulo: Academia de Polícia "Dr. Coriolano Nogueira Cobra", 2019a.

GUEBERT, J. G. V.; MOTA, J. R. G. (Coords.). Feminicídios: Diretrizes para o Atendimento de Local de Crime e Investigação de Mortes Violentas de Mulheres. São Paulo: Academia de Polícia "Dr. Coriolano Nogueira Cobra", 2019b 
LARINI, B. P. A formação profissional de policiais de polícia judiciária: estudo dos currículos da Academia da Polícia Civil do Rio Grande do Sul. Dissertação (Mestrado em Segurança Cidadã) - Instituto de Filosofia e Ciências Humanas, Universidade Federal do Rio Grande Do Sul, Porto Alegre, 2020.

LUPETTI BAPTISTA, B. G. O uso da observação participante em pesquisas realizadas na área do Direito: desafios, limites e possibilidades. In: MACHADO, M. R. (Org.). Pesquisar empiricamente o direito. São Paulo: Rede de Estudos Empíricos em Direito, 2017, p. 83-118.

MACAULAY, F.; MARTINS, J. Princípios Pedagógicos para a Formação Policial em Violência de Gênero. São Paulo: FBSP, 2018. Disponível em: https://Forumseguranca.org.br/wp-content/uploads/2018/05/ FBSP_Formacao_Policial_Violencia.Genero_port_2018.pdf. Acesso em: 14 mar. 2021.

MELO, J. J. S. de; CARVALHO, W. L. de. A educação corporativa e as políticas públicas: influências e novos desafios para a formação do profissional de segurança pública. Educação em Revista, Belo Horizonte, v. 35, jan./dez. 2019.

MOTA, J. R. G. da. La situación de vulnerabilidad de las mujeres y de las personas negras ante la actuación de los cuerpos policiales de Brasil: una aproximación desde la formación en derechos humanos. Dissertação (Mestrado em Estudos Avançados em Direitos Humanos) - Instituto de Derechos Humanos Gregorio Peces-Barba, Universidad Carlos III de Madrid, Getafe, Espanha, 2017.

NASCIMENTO, D. A.; CERQUEIRA, T. C. S. Concepções de professores da Academia de Polícia Militar de Brasília acerca de seus alunos. Educação e Pesquisa, São Paulo, v. 41, n. 4, p. 899-912, out./dez. 2015.

PEREIRA, B. C.; CRUZ, K. M. da C. Ensino Policial na Academia Integrada de Defesa Social: Instrução militar e profissionalidade docente em foco. Revista de Estudios e Investigación en Psicología y Educación, A Coruña, Espanha, v. extr., n. 6, p. 340-345, 2017.

PIRES, T. A. P. de S. O ensino Policial Civil: O Caso da Academia de Polícia Civil de Goiás. Dissertação (Mestrado em Educação) - Universidade Católica de Goiás, Goiânia, 2008.

PONCIONI, P. O modelo policial profissional e a formação profissional do futuro policial nas academias de polícia do Estado do Rio de Janeiro. Sociedade e Estado, Brasília, v. 20, n. 3, p. 585-610, set./dez. 2005.

PONCIONI, P. Tendências e desafios na formação profissional no Brasil. Revista Brasileira de Segurança Pública, São Paulo, ano 1, ed. 1, p. 22-31, 2007.

PONCIONI, P. O profissionalismo na formação profissional do policial brasileiro: rupturas, permanências e desdobramentos contemporâneos. Segurança, Justiça e Cidadania: Educação Policial, Brasília, ano 4, ก. 7, p. 47-75, 2014.

SÃO PAULO (Estado). Decreto № 60.930/2014 de 5 de julho de 1983. Reorganiza a Academia de Polícia "Dr. Coriolano Nogueira Cobra" - ACADEPOL, cria, nos Departamentos de Polícia Judiciária de S.Paulo Interior - DEINTERs 1 a 10, as unidades que especifica e dá providências correlatas. Disponível em: https://www.al.sp.gov.br/repositorio/legislacao/decreto/2014/decreto-60930-02.12.2014.html. Acesso em: 11 jan. 2022.

SÃO PAULO (Estado). Seleção de Professor Temporário de Direitos Humanos - Prot. 1328/97. Diário Oficial do Estado de São Paulo: Poder Executivo - Seção I, São Paulo, v. 107, n. 225, p. 40, 22 nov. 1997.

SÃO PAULO (Estado). Comunicado. [Instruções Especiais para o Curso Especial de Atualização para Docentes do Ensino Policial]. Diário Oficial do Estado de São Paulo: Poder Executivo - Seção I, São Paulo, v. 117, n. 127, p. 12, 7 jul. 2007. 
SÃO PAULO (Estado). Comunicado. [Instruções Especiais para o Curso Especial de Atualização para Docentes do Ensino Policial]. Diário Oficial do Estado de São Paulo: Poder Executivo - Seção I, São Paulo, v. 118, ก. 22, p. 14, 2 fev. 2008a.

SÃO PAULO (Estado). Comunicado. [Curso Especial de Atualização para Docentes do Ensino Policial]. Diário Oficial do Estado de São Paulo: Poder Executivo - Seção I, São Paulo, v. 118, n. 133, p. 5, 19 jul. 2008 b.

SÃO PAULO (Estado). Processo Acadepol 562/2012. [Edital do Processo Seletivo para Professor de Direitos Humanos]. Diário Oficial do Estado de São Paulo: Poder Executivo - Seção I, São Paulo, v. 122, n. 106, p. 22, 6 jun. 2012.

SÃO PAULO (Estado). Comunicado. [Seminário Princípios Pedagógicos para a Formação Policial em Violência de Gênero]. Diário Oficial do Estado de São Paulo: Poder Executivo - Seção I, São Paulo, v. 129, ก. 133, p. 7, 18 jun. 2019a.

SÃO PAUlO (Estado). Polícia Civil. Academia de Polícia "Dr. Coriolano Nogueira Cobra". Comunicado. [Seminário Feminicídio e a Investigação sob a Perspectiva de Gênero]. Diário Oficial do Estado de São Paulo: Poder Executivo - Seção I, São Paulo, v. 129, n. 180, p. 23, 21 set. 2019b.

SÃo PAUlO (Estado). Polícia Civil. Academia de Polícia "Dr. Coriolano Nogueira Cobra". Comunicado Processo Acadepol nº 534448/2019. [Edital de Processo Seletivo para Professor de Didática do Ensino Superior]. Diário Oficial do Estado de São Paulo: Poder Executivo - Seção I, São Paulo, v. 129, n. 232, p. 105-106, 7 dez. 2019c.

SÃO PAULO (Estado). Polícia Civil. Academia de Polícia "Dr. Coriolano Nogueira Cobra”. Deliberações da Congregação, de 24-3-2021. Diário Oficial do Estado de São Paulo: Poder Executivo - Seção I, São Paulo, v. 131, n. 60 , p. 7,27 mar. 2021.

SINHORETTO, J.; SILVESTRE, G.; SCHLITTLER M. C. Desigualdade Racial e Segurança Pública em São Paulo: Letalidade policial e prisões em flagrante. São Carlos: Grupo de Pesquisa sobre Violência e Administração de Conflitos - UFSCar, 2014.

SILVA, C. A. G. da. O ensino de direitos humanos na Polícia Civil de São Paulo: aspectos formacionais da Academia de Polícia, desafios e perspectivas. Tese (Doutorado em Direito) - Faculdade de Direito, Pontifícia Universidade Católica de Direito, São Paulo, 2007.

SILVESTRE, G. Programa de Pesquisa e Capacitação Continuada dos Policiais Civis do Estado de São Paulo em Feminicídio e a Investigação sob a Perspectiva de Gênero. In: FBSP - FÓRUM BRASILEIRO DE SEGURANÇA PÚBLICA. Práticas de enfrentamento à violência contra as mulheres: experiências desenvolvidas pelos profissionais de segurança pública e do sistema de justiça. São Paulo: FBSP, 2019, p. 61-70.

UEDA, F. dos S. Gênero líquido e a formação do policial brasileiro. Tese (Doutorado em Educação) Universidade de Sorocaba, Sorocaba, 2020.

VEIGA, C. C. P. da S.; SOUZA, J. dos S. A produção científica sobre formação dos policiais militares no Brasil. Revista Brasileira de Segurança Pública, São Paulo, v. 12, n. 1, p. 50-70, fev./mar. 2018.

VERAS, J. B. R. Docência na Polícia Militar do Ceará: Curso de Formação de Soldado de Fileiras (Turma 2007). Dissertação (Mestrado em Educação) - Universidade Estadual do Ceará, Fortaleza, 2008.
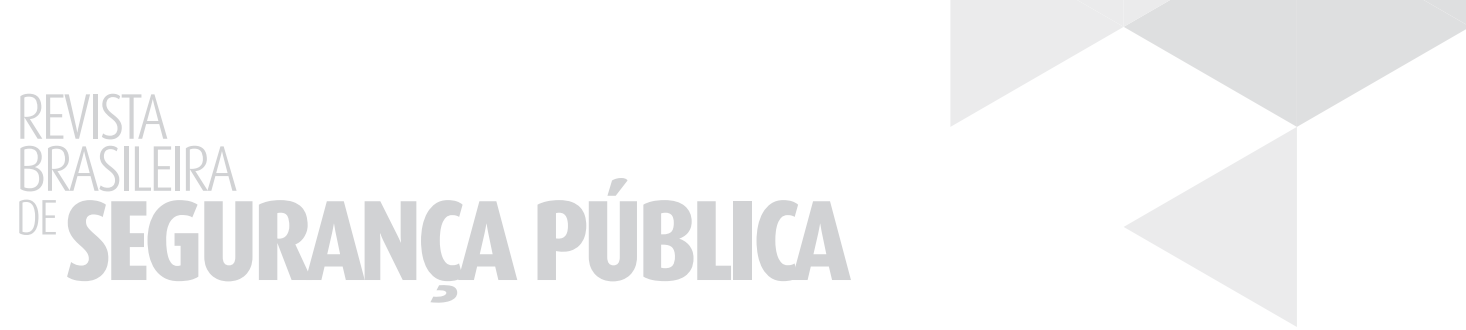